\title{
Interdisciplinary Contributions to Public Health Law
}

\author{
Susan Allan, Sana Loue, Howard Markel, Charity Scott, \\ and Martin P. Wasserman (Moderator)
}

\section{Martin P. Wasserman}

This session was created to display the value of interdisciplinary thought to the practice and teaching of public health. Through the extraordinary examples of four articulate, highly trained, and gifted individuals, the value of such training is demonstrated for the enhancement of both the individual and society. Each person describes how she or he has used the process of interdisciplinary learning, analysis, and action to enrich the substance of their personal and professional lives and the activities within their careers. Their "infectious" passion for what they do is so obvious that the audience cannot help but become personally engaged and excited. Through individual examples and stories, through discovery, analysis, science, humor, relationship-building, and values translation, each presenter briefly describes the particular path carved out and the impact that unique trail has had upon others-be they students, colleagues, or citizens in the community. Each person calls for a greater understanding of the use of interdisciplinary training and describes its resultant enhancement of the approach taken to problems faced, tackled, and resolved. One cannot help but be struck with admiration for the discipline displayed by these leaders as each uniquely pursued a dream and describes a career filled with satisfaction and pride. The listener is left with a sense of purpose and duty, "for the greater good," and perhaps even an expectation that, "I, too, can respond to the challenge," by enhancing my own knowledge base.
Susan Allan

A formal education isn't the only way to acquire skills necessary for work in public health. I have three different formal trainings. I attended law school first, then medical school. But there was still a piece missing. I was missing the perspective on small communities, the values of everyday life, and the values of public health. What I do as a local public health official uses my training in both law and medicine. In Virginia, in order to be a public health official you must be a doctor; it is not necessary to be trained in public health. After I was already working in public health, I saw this was a gap and went back to school for my master of public health degree.

Public health is a more expansive field, incorporating multiple associations and influences, which make it so interesting. The various disciplines differ in their approaches. Medicine is causal. By contrast, public health is behavioral and environmental; it is not as linear in its approach to cause and effect as the scientific protocol used in medicine. Public health uses a variety of approaches for interventions: coaching people, the creation of a collegial environment, as well as providing education and support. It is especially about teaching and coaching. By contrast, law uses a much more structured, analytical process, which leads to argumentation and to rules. There is a role in public health for law's approach in seeing how issues line up, narrowing them, then deciding how things should be on the other end. Administrative law functions are very important to public health; for example, the use 
of regulations to advance the goals. When it is necessary to close a grocery store, a lawyer understands the shorthand for these types of procedures and that moves things along.

The field of public health requires the skills of lawyers, doctors, and MPHs, intertwined and working together. Each has different analytic processes. Being conscious of these skills is important, particularly when dealing with the tough decisions that are taking place in our field.

It is important to integrate policy and law in public health education. It is also important to integrate public health into other curricula. It helps the decision-makers to understand the impact of policy issues, something that is not successfully integrated into the decision-making process. I would even recommend integrating public health into middle and high school curricula, so that the first time you hear about public health issues is not during a crisis.

Places where law integrates into public health practice include restaurant regulations. When closing restaurants it is easy to talk to the restaurant's lawyer and explain what we found and what the regulation is. As a lawyer you can see the restaurant's lawyer imagining having to explain to the judge why we should allow a dirty kitchen to continue operating, and the judge imagining eating there, which makes resolution easier. Law isn't a pre-planned machine for getting the exact answer. It is a framework which has helped allow me to build bridges and try to span the disciplines.

Public health practice is typically very collegial and polite. This is one of the virtues of the field of public health, but maybe also one of our shortcomings. We have failed to advocate for ourselves, to make what we do and why we are important more visible. As a result, other professions and the larger community don't really understand the importance and value of public health to them. By better advocacy and increased visibility, we will be presented with better linkages-with the general community, with medicine and with law. We will be better able to sell what we do and to get better interventions and regulations.

\section{Sana Loue}

I teach masters and PhD students. When I am asked for advice on what they should do with their lives, I tell my students to figure out what their core value is and figure out what the best vehicle is to express that in their lives. I have taken that advice myself. To quote a Native American colleague: "If you change the way you look at things, the things you look at will change." All of the courses that I teach are interdisciplinary.
One such example is a course entitled, "Sexuality, Public Health, and the Law." This course challenges students to draw on knowledge from a variety of disciplines, including public health, law, and bioethics in order to resolve health-related issues. Such questions might include an examination of quarantine policies for sexually-transmitted diseases such as HIV/AIDS, or health and legal issues arising in the context of the adoption of children by same-sex and opposite-sex couples.

In establishing a center for minority health, I see law, public health, and social work as mechanisms to promote social justice. I see this goal as an intersection of the disciplines, to do research as needed by the communities the center serves, and to provide a training ground for students.

There are many research issues involving both public health and law. For example, there was a study done on HIV risk and risk perception in women diagnosed with bipolar and schizophrenic disorders, a very high-risk group. The study involved using baseline interviews with the subjects, follow-up interviews, provider interviews, and the shadowing of the women. Shadowing involved watching them going places, making drug buys, and soliciting. In short, everything the women did. Many of them were dualdiagnosis subjects, having both mental illness and concomitant substance abuse. When the study lost track of them, the researchers would find them by looking anywhere they might find the homeless population.

This study presented legal issues and safety issues for the staff. If the staff is on a street corner and can only stand and watch the individual, how do they tape record a drug buy without the drug dealer knowing about it; or, what do you do if the police arrest the staff along with the subject? The subject might not want the police to know if they are HIV-positive, especially in light of mandatory disclosure laws with criminal punishments. The study has to be prepared for finding ways to get staff out of jail without violating the subject's confidences.

We have a program that provides HIV prevention information to detainees in detention facilities. Many issues arise in the context of this program that require examination from the perspectives of both law and public health. One issue is when a detainee goes to the infirmary and asks for an HIV test only to be told that he can't have one. This situation raises the legal issue of access to adequate care in a detention facility, as well as the accompanying public health issue of the control of communicable disease. In addition, if security concerns dictate that detainees share razors in order to limit access to such items, how should we 
address public health concerns related to the transmission of disease that could result from this sharing?

\section{Howard Markel}

I learned in graduate school in public health that the first word of public health is "public"-which is anything but a normative, monolithic term. Just as the public consists of many different individuals, communities and groups, so, too, does the academic enterprise. Splintering is common among all endeavors, but even more so in academia where you are rewarded for finding a tiny niche and spending your career exploring it. I am an interdisciplinarian by nature. When choosing a career, I wanted one that blended both the humanistic aspects of, as well as the practice of, medicine. When I was a resident in training there was a great amount of pressure by my teachers to become a bench scientist and, at times, this chauvinism to a single approach to an intellectual life made me somewhat hesitant to make a commitment to become a historian of medicine. But I am glad I did. You have to remember that when you do interdisciplinary studies, you are a maverick. You are alone. It can be hard going. To historians, I am seen as a doctor, and doctors view me as a historian. But I have faith in the validity of my craft and intellectual powers and consequently I look at myself as an opportunistic infection. I have to infect someone, a potential believer in the validity of conducting historical research in the context of a medical center, whenever I see the opportunity. It is well worth doing.

Whatever career you choose, you have to find what you love and do it. Although pursing an interdisciplinary path can be very discouraging, it is assuredly worth it. When I chose to pursue the history of medicine I was asked by not a few scientists, "Why do you want to study history when you can make it?" At times, I wish I responded, "Well, when I do write the history of medicine, you're not going to be in it!" I didn't have a good line at the time, but the two disciplines are really not that disparate. Today, after almost two decades of pursuing it, I do. Doctors are writing histories all the time, using different sources of data and coming to a conclusion. Historians, using newspapers and other evidence, try to come to some sense of what happened in the past. William Carlos Williams, a poet and a pediatrician, once observed that as a physician you hear stories that no one would tell you otherwise.

And another great physician, William Osler, prescribed his secret to success, although I am para- phrasing: "Take each day as it comes, work the hardest you can, try to separate what is right from what is wrong, and the success and happiness will come." This is what I have done. Find what you love, grab it; grab it and hold on to it tightly because most people don't find ever find such a valuable commodity.

\section{Charity Scott}

I have the distinction of being the only panelist here without a string of interdisciplinary degrees after my name. My professional training-a Juris Doctor degree-typifies the narrow professional training that we continue to offer law students. Despite, or perhaps because of, these limitations in my own background, I have become a great advocate and practitioner of promoting interdisciplinary education, especially on issues of health and law. With a full-time faculty position in a law school, I have also taught in graduate programs of medical ethics, health administration, and other health-related fields.

A classic poem by the nineteenth-century American poet John Godfrey Saxe, "The Blind Men and the Elephant," reflects perfectly this panel's purpose to demonstrate the need for all our professions which work at the intersection of public health and law to come together to get a complete picture of the future challenges in public health. In the poem, based on legend from India, six blind men touch a different part of the elephant, and each authoritatively concludes what the creature must be: a wall (from touching the elephant's side); a spear (from touching its tusk); a snake (from its trunk); a tree (knee); a fan (ear); and rope (tail). The poet draws the moral that while each blind man was partly right, they were all also wrong, and he reflects on the human tendency to assume that our own individual perspective tells the whole story.

Lawyers can approach a public health problem one way, epidemiologists may approach it another way, and health care providers may view the same problem from yet another vantage point. We each come to a problem from the perspective gained within our own professional silos. In order to understand a problem, however, we must learn to take a more holistic approach. This is what I attempt to do in my interdisciplinary classes. The best interdisciplinary classes are those that bring graduate students and faculty in each professional discipline together in the same classroom analyzing the same problem or issue at the same time.

There are three principal reasons to teach interdis- 
ciplinary classes. First, it is a very humbling experience. It encourages humility (a good thing!) among the faculty who engage in this experience to realize how differently other professionals may view not only a health problem, but also one's own profession. A decade ago, I took my sabbatical year in the Neonatal Intensive Care Unit (NICU) at our local downtown teaching hospital as an ethics fellow-in-residence. When doctors learned I was actually a lawyer, I was greeted initially with skepticism and even scorn. It took a while to win trust and acceptance, but once those hurdles were overcome, I had the opportunity of a lifetime to understand, up close and personally, just how challenging health care delivery can be for those on the front lines. What I experienced in the NICU cemented my belief that interdisciplinary education in medicine and law is necessary to understand our professions' respective missions, challenges, and perspectives.

Second, interdisciplinary classes are just a lot more interesting and a lot more fun. I believe people should do things that are fun, both for the teacher and for the students. When we bring medical and law students together in the same class, things get really interesting. While there may be hesitancy at first, like middleschoolers at their first dance, there is genuine curiosity about each other. From their collective willingness to share their views and concerns, they gain more from each other than the faculty could ever hope to teach them in isolation.

Third, interdisciplinary education might actually improve the public's health. For example, our law school is working with Children's Healthcare of Atlanta and the Atlanta Legal Aid Society on a Health Law Partnership (HeLP) to improve the health of lowincome children and their families. HeLP's primary premise is that by combining the health care expertise of hospital professionals with the legal expertise of attorneys, we can provide a coordinated set of services to address the physical, social, and economic determinants of low-income children's health. For example, pediatricians can address an acute episode of asthma, but it may take a lawyer to intervene with the landlord who is refusing to fix the underlying problem of illegal and unsanitary conditions in the family's apartment that keeps the child returning for medical care. This interdisciplinary educational and community service project hopes to demonstrate that doctors, lawyers, and other health professionals (and graduate students in the various disciplines) can work together on the same side of the patient, collaboratively and constructively, and can bring our professions closer together as partners in improving the community's health.

While the benefits of interdisciplinary education are great, there are also many challenges. One of the greatest challenges to interdisciplinary teaching is significant resistance to change within each of our respective professional institutional silos. Colleagues often do not understand why we are doing this, and it may look to them as if we are neglecting the basic curriculum. Administrators may also not understand; a former dean could not imagine what my professional work with someone else's medical school was doing to benefit our law school or our law students. Even if one does get support, in principle, from one's home institution, interdisciplinary education is very time-consuming and takes a tremendous amount of energy. In fact, it seems to triple the amount of effort just to get the logistics and the curriculum worked out and the faculty's and students' schedules coordinated, to say nothing of figuring out how to present material to students of widely differing training and background and grading them fairly on their work product in light of those differences.

I believe the benefits are worth our hard efforts to overcome the challenges of interdisciplinary education. Fundamentally, all of us in public health are problem-solvers, and we are all trained to think analytically. Just as the six blind men each saw the elephant differently, however, we all tend to define public health problems differently and to use our professional skills and tools to solve them in different ways. To face the public health challenges of the twenty-first century, we need to bring all of our professions togeth$\mathrm{er}$, in both work and educational settings.

The Blind Men and the Elephant By John Godfrey Saxe

It was six men of Indostan

To learning much inclined, Who went to see the Elephant (Though all of them were blind), That each by observation

Might satisfy his mind.

The First approached the Elephant, And happening to fall

Against his broad and sturdy side, At once began to bawl:

"God bless me! but the Elephant

Is very like a wall!"

The Second, feeling of the tusk

Cried, "Ho! what have we here,

So very round and smooth and sharp?

To me 'tis mighty clear

This wonder of an Elephant

Is very like a spear!" 
The Third approached the animal, And happening to take

The squirming trunk within his hands, Thus boldly up he spake:

"I see," quoth he, "the Elephant

Is very like a snake!"

The Fourth reached out an eager hand, And felt about the knee:

"What most this wondrous beast is like Is mighty plain," quoth he;

"Tis clear enough the Elephant

Is very like a tree!"

The Fifth, who chanced to touch the ear,

Said: "E'en the blindest man

Can tell what this resembles most;

Deny the fact who can,

This marvel of an Elephant

Is very like a fan!"
The Sixth no sooner had begun

About the beast to grope,

Than, seizing on the swinging tail

That fell within his scope.

"I see," quoth he, "the Elephant

Is very like a rope!"

And so these men of Indostan

Disputed loud and long,

Each in his own opinion

Exceeding stiff and strong,

Though each was partly in the right,

And all were in the wrong!

Moral:

So oft in theologic wars,

The disputants, I ween,

Rail on in utter ignorance

Of what each other mean,

And prate about an Elephant

Not one of them has seen!

From:<http://www.noogenesis.com/pineapple/blind_men_ elephant.html>. 